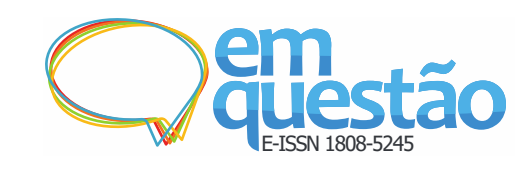

\title{
A cidadania nas pontas dos dedos: um panorama por meio dos aplicativos cívicos no Brasil
}

\author{
Sandryne Bernardino Barreto Januário \\ Mestre; Universidade Federal de Pernambuco, Recife, PE, Brasil; \\ sandrynebarreto@gmail.com \\ Renato Fernandes Correa \\ Doutor; Universidade Federal de Pernambuco, Recife, PE, Brasil; \\ renato.correa@ufpe.br
}

\begin{abstract}
Resumo: Analisa o exercício da cidadania digital no Brasil por meio dos aplicativos cívicos disponibilizados entre os anos de 2012 e 2018. A metodologia consiste em pesquisa exploratória e descritiva, baseada em pesquisa documental e análise de conteúdo. A coleta de dados se deu entre os meses de junho de 2017 e dezembro de 2018 e lançou mão de quatro fontes principais de informação. Foram identificados 27 aplicativos cívicos e analisados documentos digitais referentes aos mesmos (em sites, blogs, matérias jornalísticas e redes sociais), sendo levantadas nove categorias ou unidades de análise dos aplicativos. Os aplicativos foram categorizados e foi realizada uma análise de gráficos visando compreender o exercício da cidadania digital no país por meio dos aplicativos disponibilizados. Conclui-se que o exercício da cidadania digital no Brasil apresenta um cenário por um lado condensado em alguns valores de categorias, como os autores e temas dos aplicativos cívicos, por outro lado disperso quanto as ferramentas cívicas que possibilitam a cidadania digital no país.
\end{abstract}

Palavras-chave: Cidadania Digital. Aplicativos cívicos. Tecnologia cívica. Democracia Digital. Participação social.

\section{Introdução}

No auge de uma grave crise institucional no Brasil, iniciada em meados de 2014, em que o nosso modelo democrático se apresenta tão enfraquecido e desacreditado, falar sobre cidadania digital e democracia digital numa pesquisa científica, especialmente na área da Ciência da Informação (CI), parece ser um grande desafio. E sim, ele é tão vasto quanto instigante, justamente porque a forma de fazer democracia e de exercer a cidadania está sendo reinventada e ressignificada em tempo real. As fronteiras e características desse tema se 
transformam a cada nova possibilidade ou plataforma digital disponível, perfazendo assim o que neste trabalho se considera como cidadania digital.

A adoção crescente das tecnologias de informação e comunicação pela sociedade tem também influenciado na maneira como se exerce a cidadania digital. Nesse contexto, tem se sobressaído o uso dos aplicativos cívicos, pois são um tipo de software que possibilita aos cidadãos exercerem uma participação política por meio da cobrança e fiscalização das atividades da administração pública, acompanhamento das atividades dos poderes legislativos e judiciários ou serviço público em geral.

Diante do exposto surge a seguinte questão: como a cidadania digital tem sido exercida no Brasil, a partir dos aplicativos cívicos disponibilizados? Tendo em vista esse questionamento, o presente estudo visa compreender como a cidadania digital tem sido exercida no Brasil, por meio da análise dos aplicativos cívicos desenvolvidos.

O objetivo deste trabalho é analisar o exercício da cidadania digital a partir dos aplicativos cívicos disponibilizados no Brasil entre os anos de 2012 e 2018. Para isso, os objetivos específicos que esta pesquisa busca alcançar são:

a) estudar o contexto em que se desenvolve a Cidadania Digital no Brasil na perspectiva da Ciência da Informação;

b) identificar os aplicativos cívicos existentes;

c) descrever os aplicativos cívicos existentes

d) categorizar os aplicativos cívicos identificados por meio dos recursos humanos, técnicos e tecnológicos envolvidos;

e) analisar as informações levantadas a partir das categorias e das relações entre os aplicativos cívicos identificados e o conceito de cidadania digital.

Essa pesquisa se justifica pelo caráter social da Ciência da Informação e na abordagem da relação entre informação, memória e tecnologia. Pois está relacionada ao resgate e a visualização da memória coletiva dos cidadãos que por meio da tecnologia dos aplicativos cívicos estão experimentando e construindo novos conceitos de informação pública e cidadania digital no Brasil.

\section{Fundamentação teórica}


No contexto da cidadania digital, para além dos desafios da definição de cidadania, tem-se uma temática ainda recente, em contínuo desenvolvimento e que somente há poucos anos começou a despertar a atenção da comunidade acadêmica. Questões como a inclusão e a exclusão digital, a segurança da informação, a privacidade dos dados, os direitos e os deveres dos cidadãos exercidos em meio digital e o impacto cultural disso tudo na sociedade são centrais para a compreensão das mudanças conceituais em curso.

Nesse estudo, tendo como foco os direitos e deveres cívicos do cidadão em meio digital, a definição de cidadania digital que melhor se aplica é a dos professores Ângela Grossi de Carvalho e Marco Américo. Eles acreditam que a cidadania digital é a "ampliação dos direitos já conquistados nos campos sociais, político, econômico e cultural para as redes digitais, utilizando-se das tecnologias de informação e comunicação" (CARVALHO, AMÉRICO, 2014, p.72).

Isso posto, é importante refletir não apenas sobre o que é a cidadania, especialmente hoje, no contexto mutável e sem barreiras físicas no qual vivemos graças à Internet, mas como exercer essa cidadania na conjuntura atual. Pois a cidadania é um direito que não necessariamente deve ser "dado" pelo governo, até porque ele possivelmente não seria entregue em sua completude ou viria sem interesse. Uma sociedade educada de seus direitos é o que proporciona a cidadania ser verdadeiramente construída e apropriada, sendo a informação fundamental nesse processo. De acordo com Rocha (2000),

Essa conscientização é um processo que permite ao homem compreender a realidade que o cerca, como ela se estrutura e como reagir a essa realidade, assumindo o seu destino e o dos seus semelhantes com autonomia, buscando melhores condições de vida (ROCHA, 2000, p.42)

Numa perspectiva de contribuição para um governo efetivamente democrático alinhado a essa conscientização cidadã, acredita-se que isso parte do acesso e do uso da informação pública, pois é a partir daí que o cidadão poderá se instrumentar e desenvolver o seu senso crítico, propondo ações, expondo críticas, sugerindo mudanças, acompanhando o cumprimento de metas, 
fiscalizando ações governamentais, entre outras atividades que fazem parte do seu rol de direitos e deveres enquanto cidadão. Pois só é possível participar daquilo que se tem conhecimento, como afirmam Borges e Silva (2006), o acesso à informação é o próprio viabilizador do regime democrático, se admitir que esse esteja alicerçado na participação popular de forma consciente.

É nesse contexto que se apresenta o ambiente digital escolhido para essa pesquisa, os aplicativos cívicos, por possibilitarem aos cidadãos uma maior participação na vida política da sua cidade, região ou país, seja por meio da cobrança e fiscalização das atividades da administração pública, seja no acompanhamento das atividades dos poderes legislativos e judiciários ou ainda quanto ao serviço público em geral (GOMES, SCHNEIDER, BEZERRA, 2018).

E é visando essa boa governança por meio de uma efetiva cidadania digital que as tecnologias de informação e comunicação (TIC), inclusive por meio dos aplicativos cívicos, estão cada vez mais atreladas à promoção dos direitos civis, políticos e sociais. Isso porque as TIC possibilitam de modo atemporal e sem fronteiras o uso da informação pública proporcionando uma maior transparência dessas informações, assim como uma crescente conscientização da sociedade quanto à sua responsabilidade na administração dos bens e serviços públicos.

Testa (2007) corrobora com esse entendimento ao afirmar que a cidadania digital surgiu como uma nova dimensão social e política que "explicita um novo jeito de ser e se qualifica pelo acesso autônomo ao mundo virtual e a toda a sua complexidade[...]" (TESTA, 2007, p. 68). O autor acredita que isso acabou produzindo um importante impacto psicossocial que afetou o comportamento do cidadão.

Nessa perspectiva, a Ciência da Informação tem um papel fundamental por ser uma ciência, dentre outras características, interdisciplinar, tecnológica e social, voltada para o objeto informação e aspectos envolvidos, tais como o acesso, o uso, a organização, a recuperação e o compartilhamento. Sendo tais aspectos basilares para a promoção da cidadania digital e para uma efetiva democracia digital. 
Na literatura de Ciência da Informação foram encontrados na última década 11 trabalhos sobre cidadania digital e democracia na web, com foco na participação social do cidadão: Gomes, Schneider e Bezerra (2018); Parra Filho e Martins (2017); Ribeiro (2017); Barros (2016); Brisola (2016); Moreira (2015); Cerquinho, Tavares e De Paula (2014); Azevedo (2012); Jambeiro, Sombreira e Macambira, (2011); Santos (2011); Carvalho e Santos (2009). Uma discussão mais detalhada acerca desses trabalhos pode ser encontrada no artigo de Januário e Correa (2020).

Dentre esses trabalhos, cinco deles, os de autoria de Parra Filho e Martins (2017), Barros (2016), Cerquinho, Tavares e De Paula (2014), Azevedo (2012), Jambeiro, Sombreiro e Macambira (2011), e Santos (2011), aproximam-se entre si quanto aos estudos de casos ou na análise de plataformas digitais específicas que visam promover a participação social no Brasil e no mundo.

Já dois estudos, os de Ribeiro (2017) e Moreira (2015), fizeram um panorama, com abrangências e objetivos distintos, para buscar entender uma realidade, ora de participação política, ora do uso dos dados governamentais abertos, ambos num contexto de cidadania digital e democracia digital.

A maior parte dos trabalhos relacionados apontam problemáticas que impactam diretamente no exercício da cidadania digital, dentre elas: a baixa qualidade informacional e governamental dos sites das capitais brasileiras como apresentado na pesquisa de Jambeiro, Sobreira e Macambira (2011); a falta de efetividade de dispositivos interativos dos websites de parlamentares, não garantindo que as demandas e sugestões dos cidadãos sejam respondidas pelo Governo, dissertado por Santos (2011); e também a consideração de Cerquinho, Tavares e De Paula (2014) e Ribeiro (2017), da possibilidade de plataformas governamentais estarem cercadas de um discurso de participação sem efeitos práticos, com pouca ou nenhuma influência no processo de decisão política, o que impacta diretamente na cidadania digital.

Por outro lado, foram apresentados no estudo de Moreira (2015), resultados que demonstraram a consolidação e a tendência de ampliação do uso dos dados governamentais abertos (DGA), apontando um modelo de governança caracterizado pelo envolvimento de atores estatais e não estatais, o que 
representa um grande avanço para a cidadania digital no Brasil. Já Gomes, Schneider e Bezerra (2018), adicionalmente pontuaram sobre a pouca reflexão sobre a utilização de aplicativos cívicos no Brasil e como estudos sobre a construção de cada aplicativo e o acesso a ele podem trazer novas perspectivas para a cidadania digital.

Diante desse cenário, o desafio dessa pesquisa é trilhar caminhos que busquem discutir o papel das tecnologias de informação e comunicação no fortalecimento das práticas democráticas, ampliando as possibilidades de exercício da cidadania e da democracia em ambientes digitais, numa perspectiva informacional. E num contexto de questionamento - que não é recente - dos modelos políticos tradicionais, as novas tecnologias digitais começam a ser apropriadas por representantes políticos e membros da sociedade civil na tentativa de modificar o cenário político (CASTELLS, 2001).

Por isso, vinte anos após a disseminação da Internet em todo o mundo, sem esquecer a desigualdade que há em torno disso, o surgimento de diferentes formas de organização política por meio do uso de ferramentas online tem sido cada vez mais estudado nas diversas áreas do conhecimento científico. Essa pesquisa, no escopo da Ciência da Informação, realiza uma análise do exercício da cidadania digital no Brasil a partir dos aplicativos cívicos disponibilizados.

\section{Metodologia}

O objeto de estudo desta pesquisa é o exercício da cidadania digital a partir de aplicativos cívicos disponibilizados no Brasil. O critério de seleção desse tipo de aplicativo está relacionado ao seu uso como ferramenta tecnológica para o exercício da cidadania, dado que o uso de aparelho celular se constitui como a principal fonte de acesso à Internet no Brasil. A metodologia consiste em pesquisa exploratória e descritiva, baseada em pesquisa documental e análise de conteúdo.

Para delimitar a coleta de dados, foram selecionados os aplicativos disponibilizados no Brasil entre os anos de 2012 a 2018. O ano inicial de 2012 foi escolhido devido à promulgação da Lei de Acesso a Informação (LAI), 
realizada em novembro de 2011, que proporcionou o uso legal de dados e informações públicas para os mais diversos fins, por meio de produtos e serviços.

A coleta dos documentos sobre os aplicativos cívicos foi realizada entre os meses de junho de 2017 e dezembro de 2018. Este estudo lançou mão de quatro fontes principais de informações para o levantamento dos dados.

As fontes principais foram selecionadas a partir da pesquisa de Moreira (2015), acrescido do site Hackathon.com. Tal site foi selecionado por apresentar dados de eventos de Hackathon realizados no Brasil e em mais de 30 países em todo o mundo, estando os dados atualizados e abrangendo o período de recorte da pesquisa. Hackathon é espécie de maratona de programação voltada para discutir ideias e desenvolver projetos de software, dentre eles os aplicativos, nas mais diversas áreas e temáticas. Tais eventos são importantes cenários para o desenvolvimento de aplicativos nas mais diversas temáticas, dentre elas em categorias que abrangem a cidadania digital, razão pela qual era importante constar como uma das fontes de coleta de informação.

As fontes secundárias de informação foram por meio da indicação de aplicativos cívicos por terceiros, posts em redes sociais, ou acesso a reportagens sobre aplicativos cívicos em veículos de comunicação. No Quadro 1 são apresentadas as fontes principais de informação utilizadas na coleta dos dados.

Quadro 1 - Fontes de Informação para coleta de dados

\begin{tabular}{|c|c|}
\hline Fonte de Informação & Resumo Descritivo \\
\hline $\begin{array}{l}\text { Observatório de Gestão da } \\
\text { Informação (OBGI) }\end{array}$ & $\begin{array}{l}\text { O Observatório de Gestão da Informação (OBGI) é um } \\
\text { espaço de estudos interdisciplinares sobre Gestão e } \\
\text { Políticas Públicas de Informação coordenado pela } \\
\text { Universidade Federal do Rio de Janeiro (UFRJ/IBICT) }\end{array}$ \\
\hline Portal Brasileiro de Dados Abertos & $\begin{array}{l}\text { O Portal Brasileiro de Dados Abertos é uma ferramenta } \\
\text { que visa possibilitar a todos os cidadãos o acesso a dados } \\
\text { e informações públicas. Dentre os dados } \\
\text { disponibilizados, destacam-se os temas relacionados à } \\
\text { saúde, transporte, educação, gastos governamentais e } \\
\text { processos eleitorais. }\end{array}$ \\
\hline Alerta Google & $\begin{array}{l}\text { O Alerta Google envia e-mails quando o motor de busca } \\
\text { do Google encontra novos resultados em páginas da } \\
\text { Web, artigos de jornal, revistas ou blogs, para os termos } \\
\text { escolhidos no cadastro do alerta. Para essa pesquisa } \\
\text { foram cadastrados os seguintes alertas: "aplicativo } \\
\text { cívico", "tecnologia cívica", "participação social", }\end{array}$ \\
\hline
\end{tabular}


Site Hackathon.com

"cidadania digital", "democracia digital", "dados governamentais abertos", "aplicativo social", "Hackathon", "Hackathon cívico

Uma plataforma de organização e divulgação de Hackathon que atua em 35 (trinta e cinco) países. No site é possível selecionar o país e o ano para visualizar os eventos realizados.

Fonte: Elaborado pelos autores.

Para a organização e classificação dos aplicativos identificados foram utilizadas nove categorias ou unidades de análise. Essas categorias e respectivos valores foram levantados por meio da análise de conteúdo do texto descritivo dos aplicativos nas fontes. Tais categorias foram selecionadas sob a justificativa de possibilitarem, ao mesmo tempo, a quantificação e análise qualitativa das informações descritivas desse tipo de aplicativo. A descrição dos aplicativos se deu por meio do preenchimento de uma tabela no software Excel. O Quadro 2 apresenta as categorias ou unidades de análise e a descrição de cada uma delas.

Quadro 2 - Unidades de análise para descrição e classificação dos aplicativos

\begin{tabular}{|c|c|}
\hline Categoria & Descrição \\
\hline Identificação temática do aplicativo & $\begin{array}{l}\text { Tema principal do aplicativo. Por exemplo: Segurança } \\
\text { Pública. Saúde. Educação. }\end{array}$ \\
\hline Esfera da Administração Pública & $\begin{array}{l}\text { Abrangência federal, estadual ou municipal, descrita com } \\
\text { os nomes dos estados e cidades }\end{array}$ \\
\hline Autor do aplicativo & $\begin{array}{l}\text { Indivíduo e/ou pessoa jurídica (empresas públicas, } \\
\text { privadas, governamentais, não governamentais, etc.) } \\
\text { responsáveis pelo desenvolvimento do aplicativo. }\end{array}$ \\
\hline Ano & $\begin{array}{l}\text { Ano de disponibilização do aplicativo para download e } \\
\text { não necessariamente o ano do desenvolvimento do } \\
\text { software }\end{array}$ \\
\hline Tipo de Licença & Se o software é gratuito ou pago (se paga para utilizar). \\
\hline Sistema operacional para uso & $\begin{array}{l}\text { Se o aplicativo faz uso do sistema operacional iOS, } \\
\text { Android ou outros. }\end{array}$ \\
\hline Ferramentas cívicas & $\begin{array}{l}\text { Funcionalidades e recursos de participação social que } \\
\text { possibilitam a cidadania digital por meio do aplicativo } \\
\text { cívico. As ferramentas cívicas são: Cobrança; } \\
\text { Fiscalização; } \\
\text { Acompanhamento; Denúncia; Transparência. }\end{array}$ \\
\hline Fontes de Dados & $\begin{array}{l}\text { Dados que alimentam os aplicativos cívicos. Por } \\
\text { exemplo: DGA, dados produzidos pela interação entre o } \\
\text { cidadão e a Administração Pública, dados produzidos } \\
\text { pela interação entre cidadãos. }\end{array}$ \\
\hline Status do Aplicativo & Ativo ou inativo \\
\hline
\end{tabular}

Fonte: Elaborado pelos autores. 
A pesquisa consistiu em três etapas, a saber: Levantamento dos dados; Exploração do material e categorização; e Análise dos resultados. As etapas serão descritas nas subseções que se seguem.

\subsection{Etapa 1 - Levantamento dos Dados}

Nessa etapa, buscou-se a identificação dos aplicativos cívicos desenvolvidos no Brasil entre os anos de 2012 a 2018. Uma vez identificados, os nomes e links dos sites dos aplicativos foram tabulados numa tabela no Excel.

Na primeira fonte de informação, o site hackathon.com, a pesquisa se deu pelos Hackathon promovidos no Brasil, a partir do preenchimento do nome do local. Uma vez pesquisado pelo nome "Brasil", o site apresenta os eventos em ordem cronológica do evento mais atual para o mais antigo, com um resumo do evento e a cidade em que foi realizado. A identificação dos aplicativos cívicos desenvolvidos em cada Hackathon se deu a partir da leitura individual desses resumos.

No site do Observatório de Gestão da Informação, da UFRJ, a identificação dos aplicativos cívicos se deu por meio da pesquisa na aba "produção intelectual" localizada no menu da homepage. Neste link, as produções intelectuais são apresentadas por ano, de forma decrescente. Foram analisados todos os trabalhos produzidos e alimentados no OBGI entre os anos de 2012 a 2016, uma vez que o site não tem sido mais atualizado desde então. Os aplicativos cívicos identificados nas produções intelectuais de docentes e discentes que integram o OBGI foram selecionados.

No Portal Brasileiro de Dados Abertos é possível encontrar as abas Aplicativos e Concursos. Essas páginas são alimentadas com aplicativos e concursos que utilizam os DGA para o desenvolvimento de seus produtos e serviços. Ambas as abas foram acompanhadas desde setembro de 2017 e as coletas finais se deram no mês de dezembro de 2018. Na aba Aplicativo são disponibilizados uma imagem e um resumo sobre a função e temática do software. Na aba Concursos também é possível encontrar uma imagem e um resumo do evento. Todos os resumos, de aplicativos e concursos, foram lidos e 
os aplicativos cuja temática estava relacionada a atuação cívica do cidadão, foram selecionados.

No Alerta Google foram cadastrados 9 (nove) expressões - aplicativo cívico", "tecnologia cívica", "participação social”, "cidadania digital”, "democracia digital", "dados governamentais abertos", "aplicativo social", "Hackathon", "Hackathon cívico" - na perspectiva de recuperar a maior quantidade possível de conteúdo sobre aplicativos cívicos desenvolvidos no Brasil. Os alertas são enviados por e-mail e chegam na caixa de entrada principal. No título do e-mail é apresentado o termo cadastrado correspondente e no corpo do mesmo é apresentada uma lista de links para páginas ou matérias, descritas pelo título original e um trecho do documento em que o termo pode ser encontrado. Por essas informações já era possível perceber se o conteúdo entraria ou não na coleta dos dados. Assim, todo conteúdo de provável contribuição foi aberto na página de origem e lido para identificar os aplicativos cívicos. Uma vez identificado, o nome e o link da página do aplicativo foi registrado.

\subsection{Etapa 2 - Exploração do material e categorização}

Nessa etapa metodológica, explicita-se a organização e a descrição das categorias dos aplicativos cívicos identificados na etapa descrita anteriormente.

Uma vez identificados os aplicativos por meio das quatro principais fontes de informação e das fontes secundárias de informação, todos os aplicativos foram organizados por nome e endereço eletrônico numa tabela no software Excel. A partir daí foram acrescentadas as nove categorias ou unidades de análise apresentadas no Quadro 2 para descrição dos aplicativos na tabela:

a) Identificação da temática do aplicativo;

b) A esfera da Administração Pública;

c) A descrição do autor do aplicativo;

d) Ano de disponibilização;

e) O tipo de licença;

f) O sistema operacional para uso; 
g) Ferramentas cívicas disponíveis;

h) Fonte de dados;

i) Status do aplicativo.

Assim, todos os documentos (páginas web, matérias jornalísticas, posts em redes sociais etc.) sobre os aplicativos cívicos levantados na etapa 1 foram lidos e analisados, de modo a identificar as informações necessárias ao preenchimento de cada categoria através do procedimento da análise de conteúdo.

\subsection{Etapa 3 - Análise dos resultados}

Após os procedimentos indicados na etapa 2 , realizou-se a representação em gráficos das categorias dos aplicativos cívicos organizados, visando as suas interpretações de acordo com os objetivos propostos por esta pesquisa.

Com a tabela preenchida com todas as categorias descritas, utilizou-se dos gráficos do software Excel para visualizar as informações de cada categoria quantitativamente e interpretá-las qualitativamente por meio de suas particularidades, diferenças e semelhanças, de modo a apresentar um panorama fidedigno à realidade da cidadania digital no Brasil.

\section{Análise dos resultados}

Inicialmente os aplicativos foram organizados por ordem alfabética por meio do nome do aplicativo, um breve resumo descritivo e o endereço eletrônico, como podem ser observados no Quadro 3.

Quadro 3 - Panorama dos aplicativos cívicos disponibilizados no Brasil

\begin{tabular}{|l|l|l|}
\hline \multicolumn{1}{|c|}{ Aplicativo } & \multicolumn{1}{|c|}{ Resumo descritivo } & \multicolumn{1}{|c|}{ Endereço eletrônico } \\
\hline Cidade Legal & $\begin{array}{l}\text { Aplicativo colaborativo para o cidadão } \\
\text { relatar os problemas da sua cidade. }\end{array}$ & http://cidadelegal.com/ \\
\hline Cidadera & $\begin{array}{l}\text { Aplicativo que tem como objetivo } \\
\text { mapear os problemas urbanos da cidade } \\
\text { de forma colaborativa. }\end{array}$ & $\begin{array}{l}\text { https://itunes.apple.com/br } \\
\text { /app/cidadera/id68293944 } \\
9 ? m t=8\end{array}$ \\
\hline Colab & $\begin{array}{l}\text { Aplicativo voltado para a participação } \\
\text { social em que o cidadão apresenta } \\
\text { demandas do município para serem } \\
\text { solucionadas pela prefeitura }\end{array}$ & htt/www.colab.re/ \\
\hline
\end{tabular}




\begin{tabular}{|c|c|c|}
\hline Desenvolve Brasil & $\begin{array}{l}\text { Aplicativo que apresenta os } \\
\text { empreendimentos de infraestrutura e } \\
\text { permite o acompanhamento da evolução } \\
\text { das obras nos estados e municípios. }\end{array}$ & $\begin{array}{l}\text { https://play.google.com/sto } \\
\text { relapps/details?id=br.gov. } \\
\text { desenvolvebrasil\&hl=pt_B } \\
R\end{array}$ \\
\hline $\begin{array}{l}\text { Detector de Ficha de } \\
\text { Político }\end{array}$ & $\begin{array}{l}\text { Aplicativo que visa viabilizar aos } \\
\text { cidadãos o acesso às informações } \\
\text { relativas a processos de seus possíveis } \\
\text { candidatos }\end{array}$ & $\begin{array}{l}\text { http://www.vigieaqui.com. } \\
\text { br/detectordefichadepolitic } \\
o\end{array}$ \\
\hline Estação Cidadania & $\begin{array}{l}\text { Aplicativo com } \text { a } \\
\text { disponibilizar à população do estado do } \\
\text { Pará informações e serviços públicos, } \\
\text { mediante a integração de diversos } \\
\text { órgãos. }\end{array}$ & $\begin{array}{l}\text { http://www.estacaocidada } \\
\text { nia.pa.gov.br/ }\end{array}$ \\
\hline Fala Cidadão & $\begin{array}{l}\text { Aplicativo colaborativo com o objetivo } \\
\text { de auxiliar prefeituras e cidadãos a terem } \\
\text { uma comunicação mais eficiente, a partir } \\
\text { de alertas criados pela população para } \\
\text { definir quais problemas e melhorias que } \\
\text { merecem atenção prioritária. }\end{array}$ & $\begin{array}{l}\text { https://www.falacidadaoap } \\
\text { p.com.br/ }\end{array}$ \\
\hline Fiscalize, Fortaleza & $\begin{array}{l}\text { Aplicativo que atua como canal de } \\
\text { comunicação entre o cidadão e a } \\
\text { Prefeitura de Fortaleza para tratar de } \\
\text { temas referentes ao controle urbano e } \\
\text { vigilância sanitária. }\end{array}$ & $\begin{array}{l}\text { https://denuncia.agefis.fort } \\
\text { aleza.ce.gov.br/\#/ }\end{array}$ \\
\hline Infoleg & $\begin{array}{lll}\text { Aplicativo com informações das } \\
\text { atividades legislativas da Câmara dos } \\
\text { Deputados }\end{array}$ & $\begin{array}{l}\text { https://www2.camara.leg.b } \\
\text { r/infoleg }\end{array}$ \\
\hline Meu Deputado & $\begin{array}{l}\text { Aplicativo que visa manter os cidadãos } \\
\text { informados a respeito dos gastos } \\
\text { públicos mensais dos deputados federais. }\end{array}$ & https://meudeputado.mobi \\
\hline Monitora Brasil & $\begin{array}{l}\text { Aplicativo que visa o combate a } \\
\text { corrupção e a transparência por meio da } \\
\text { fiscalização das atividades dos } \\
\text { Deputados Federais. }\end{array}$ & https://monitorabrasil.org/ \\
\hline MPF Serviços & $\begin{array}{l}\text { Aplicativo para realizar denúncias e } \\
\text { solicitar investigação do Ministério } \\
\text { Público Federal, na esfera judicial. }\end{array}$ & $\begin{array}{l}\text { http://www.mpf.mp.br/mpf } \\
\text { servicos }\end{array}$ \\
\hline Mudamos & $\begin{array}{l}\text { Aplicativo que coleta assinaturas } \\
\text { eletrônicas em projetos de lei de } \\
\text { iniciativa popular }\end{array}$ & https://www.mudamos.org/ \\
\hline Obras do PAC & $\begin{array}{l}\text { Aplicativo que possibilita o } \\
\text { acompanhamento das obras do Programa } \\
\text { de Aceleração do Crescimento (PAC) }\end{array}$ & $\begin{array}{l}\text { http://dados.gov.br/aplicat } \\
\text { ivo/painel-do-pac }\end{array}$ \\
\hline $\begin{array}{l}\text { Opine aíl } \\
\text { Tô no controle }\end{array}$ & $\begin{array}{l}\text { Aplicativo que possibilita ao cidadão se } \\
\text { manifestar sobre serviços públicos } \\
\text { municipais e estaduais em Rondônia, em } \\
\text { áreas como educação, saúde, segurança, } \\
\text { transporte público. }\end{array}$ & $\begin{array}{l}\text { https://play.google.com/sto } \\
\text { relapps/details?id=br.gov. } \\
\text { ro.tce.tonocontrole.opineai }\end{array}$ \\
\hline $\begin{array}{l}\text { Para onde foi o meu } \\
\text { dinheiro }\end{array}$ & $\begin{array}{l}\text { Aplicativo que ajuda o cidadão a } \\
\text { monitorar a execução dos orçamentos } \\
\text { municipal, estadual e federal. }\end{array}$ & $\begin{array}{l}\text { http://paraondefoiomeudin } \\
\text { heiro.org.br/ }\end{array}$ \\
\hline
\end{tabular}




\begin{tabular}{|c|c|c|}
\hline Poder do voto & $\begin{array}{l}\text { Aplicativo que permite o } \\
\text { acompanhamento dos principais projetos } \\
\text { de lei que estão sendo discutidos no } \\
\text { Congresso Nacional e interação com os } \\
\text { parlamentares, enviando mensagens e } \\
\text { fiscalizando como eles estão votando. }\end{array}$ & $\begin{array}{l}\text { https://www.poderdovoto.o } \\
\text { rg/ }\end{array}$ \\
\hline Portal da Cidadania & $\begin{array}{l}\text { Aplicativo que visa facilitar a vida do } \\
\text { cidadão quanto à solicitação de serviços } \\
\text { e informações da administração pública } \\
\text { do Estado da Paraíba. }\end{array}$ & $\begin{array}{l}\text { https://portaldacidadania. } \\
\text { pb.gov.br/ }\end{array}$ \\
\hline Portal do Cidadão & $\begin{array}{l}\text { Aplicativo com a finalidade de oferecer } \\
\text { aos munícipes da cidade de Campinas } \\
\text { (São Paulo) um canal para consumo de } \\
\text { serviços, solicitações } \\
\text { acompanhamentos. }\end{array}$ & $\begin{array}{l}\text { https://cidadao.campinas.s } \\
\text { p.gov.br/ }\end{array}$ \\
\hline Prefeitura de Jundiaí & $\begin{array}{l}\text { Aplicativo com a finalidade de oferecer } \\
\text { aos munícipes da cidade de Jundiaí (São } \\
\text { Paulo) um canal para consumo de } \\
\text { serviços, solicitações } \\
\text { acompanhamentos. }\end{array}$ & $\begin{array}{l}\text { https://play.google.com/sto } \\
\text { re/apps/details? } \text { id=br.gov. } \\
\text { sp.cijun.appjun }\end{array}$ \\
\hline Radar Parlamentar & $\begin{array}{l}\text { Aplicativo que apresenta a semelhança } \\
\text { entre os partidos políticos no Brasil por } \\
\text { meio dos votos que ocorrem no } \\
\text { Congresso Nacional. }\end{array}$ & $\begin{array}{l}\text { http://radarparlamentar.p } \\
\text { olignu.org/ }\end{array}$ \\
\hline Siga Brasília & $\begin{array}{l}\text { Aplicativo que disponibiliza informações } \\
\text { quanto às despesas e receitas públicas, } \\
\text { remuneração dos servidores e a escala } \\
\text { dos profissionais de saúde em Brasília }\end{array}$ & $\begin{array}{l}\text { http://sigabrasilia.df.gov.b } \\
r /\end{array}$ \\
\hline SINCOV Cidadão & $\begin{array}{l}\text { O aplicativo que fornece transparência } \\
\text { sobre as transferências voluntárias } \\
\text { operacionalizadas, além de informações } \\
\text { sobre os instrumentos celebrados entre o } \\
\text { governo federal e os governos estaduais, } \\
\text { municipais e organizações da sociedade } \\
\text { civil. }\end{array}$ & $\begin{array}{l}\text { http://portal.convenios.gov } \\
\text {.br/home-cidadao }\end{array}$ \\
\hline SP 156 & $\begin{array}{l}\text { Aplicativo que permite aos cidadãos } \\
\text { contribuírem com a gestão da cidade de } \\
\text { São Paulo, a partir da solicitação de } \\
\text { serviços, reclamações e denúncias. }\end{array}$ & $\begin{array}{l}\text { https://sp156.prefeitura.sp. } \\
\text { gov.br/portal/servicos }\end{array}$ \\
\hline Sr Cidadão & $\begin{array}{llr}\text { Aplicativo que } & \text { oferece } & \text { o } \\
\text { acompanhamento das } & \text { atividades de } \\
\text { políticos, selecionados } & \text { por estado e } \\
\text { partido. } & \end{array}$ & $\begin{array}{l}\text { http://www.srcidadao.com. } \\
\text { br/ }\end{array}$ \\
\hline $\begin{array}{l}\text { Tá de Pé: Fiscalize a } \\
\text { escola }\end{array}$ & $\begin{array}{l}\text { Aplicativo para fiscalização de obras de } \\
\text { escolas e creches públicas. }\end{array}$ & $\begin{array}{l}\text { https://www.transparencia. } \\
\text { org.br/projetos/tadepe }\end{array}$ \\
\hline Tô de olho & $\begin{array}{l}\text { Aplicativo de acompanhamento das } \\
\text { ações dos vereadores do Rio de Janeiro }\end{array}$ & $\begin{array}{l}\text { https://benfeitoria.com/tod } \\
\text { eolho }\end{array}$ \\
\hline
\end{tabular}

Posteriormente, os aplicativos foram descritos com base nas informações coletadas, perfazendo todas as categorias ou unidades de análise pré- 
determinadas para uma posterior análise dos dados. As subseções a seguir apresentam a análise dos aplicativos cívicos de acordo com cada categoria.

\subsection{Temática do aplicativo}

Quanto aos temas dos aplicativos, identificaram-se sete temáticas. O tema interação urbana está relacionado aos aplicativos que possibilitam a comunicação do cidadão com os representantes legais das cidades, seja para a solicitação de uma informação, seja para a resolução de um problema de ordem pública, mas cuja atividade principal perpasse por essa relação interativa.

Dos 27 aplicativos analisados, 21 deles, o que corresponde a 78\%, estão concentrados em três temáticas: política partidária, serviço público e interação urbana. Num universo de possibilidades temáticas tão extensas em questões de cidadania digital, acredita-se que esse quantitativo de temas é pequeno e concentrado.

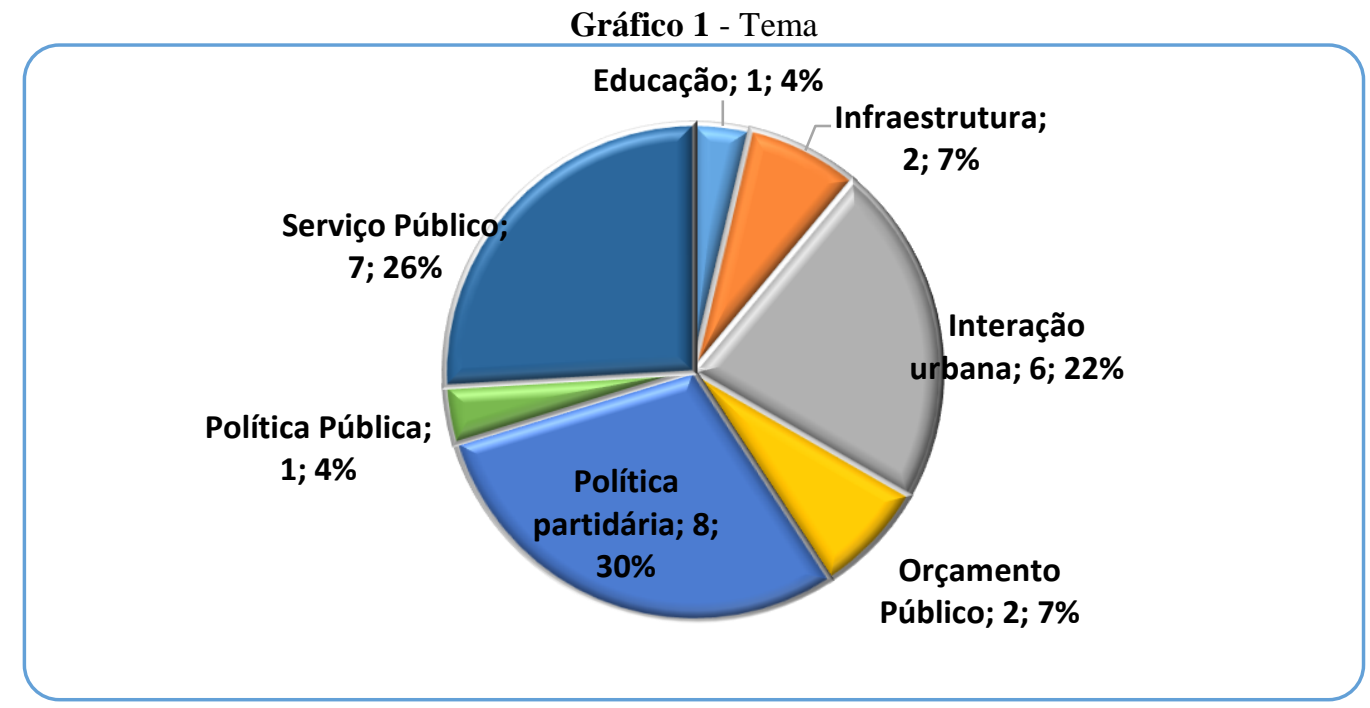

Fonte: Elaborado pelos autores.

\subsection{Esfera da Administração Pública}

Além das três esferas da Administração pública em que os aplicativos podem atuar, observou-se a junção de uma ou mais esferas, a depender da especificidade de ação de cada plataforma. A atuação a nível federal correspondeu a quase metade dos aplicativos analisados, assim como as 
atividades realizadas em mais de uma esfera correspondeu a apenas $2 \%$ da análise. Isso possivelmente se justifica na escolha de um foco de atuação territorial por quem desenvolve os aplicativos.

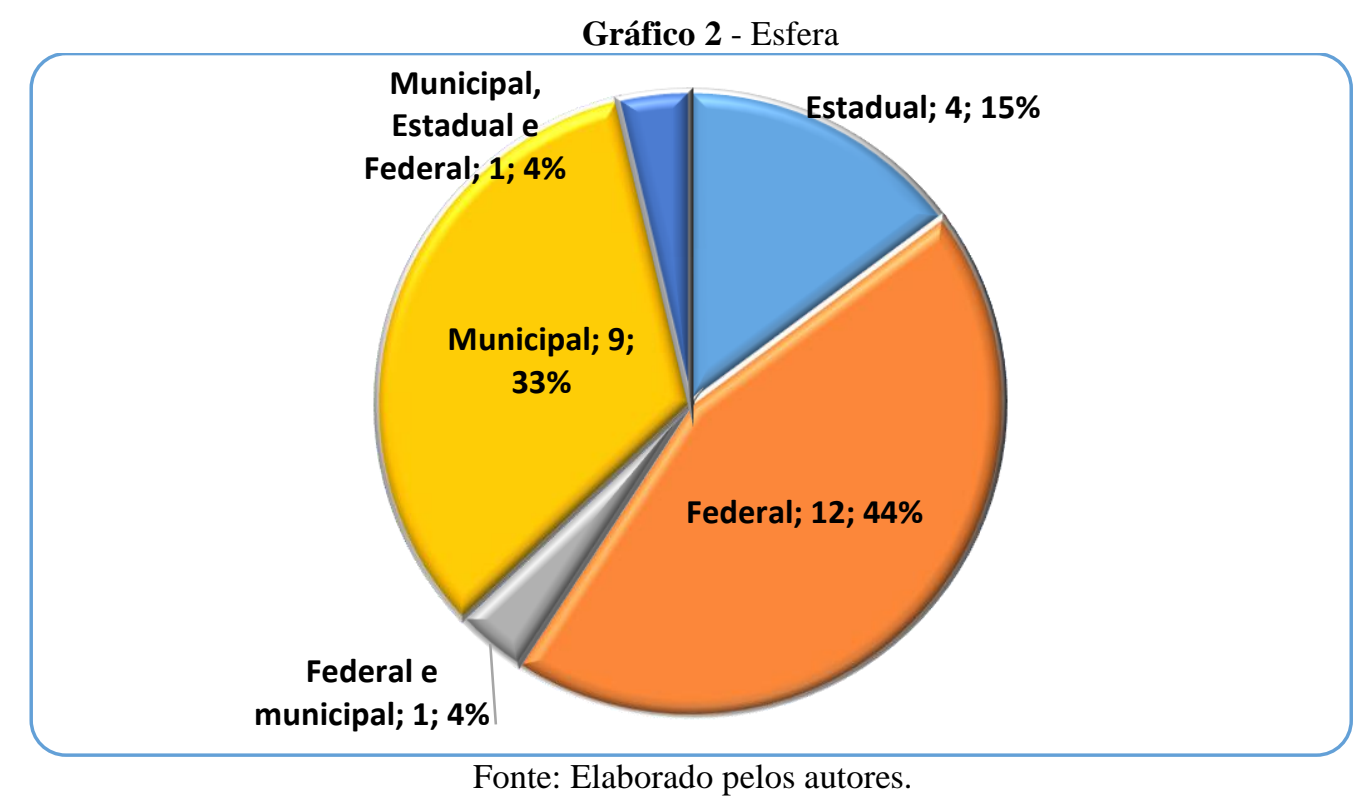

\subsection{Tipo de autoria}

Os autores dos aplicativos foram divididos em cinco grupos e o grupo de autores organização pública representa quase a metade dos responsáveis pelo desenvolvimento desse tipo de aplicativo no país. Porém, a soma do percentual de indivíduos, especialmente advindos de eventos como Hackathon, junto às organizações não governamentais representam $30 \%$ da autoria ao passo que as organizações privadas atingem $29 \%$ da autoria, um quantitativo significativo para o desenvolvimento da cidadania digital. 


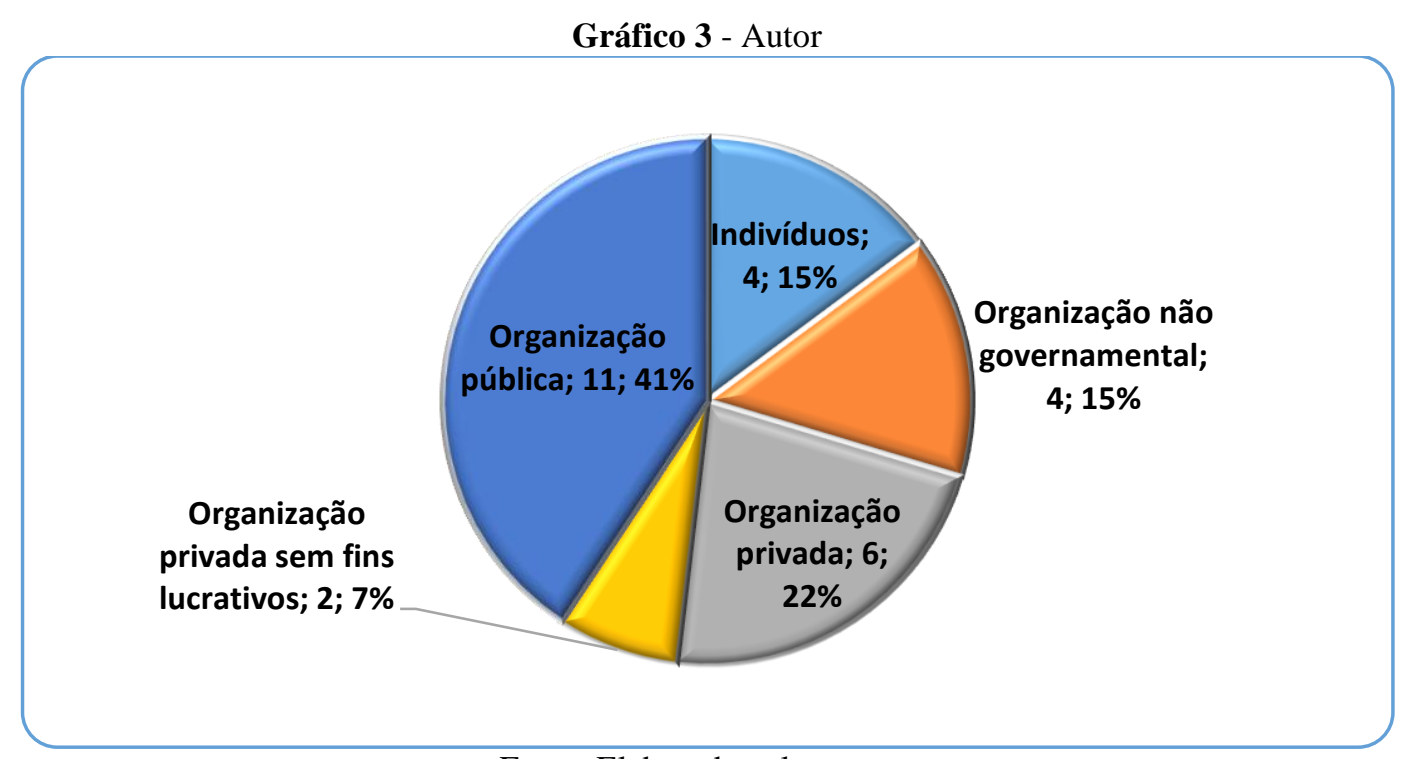

Fonte: Elaborado pelos autores.

\subsection{Ano}

Pode-se observar que nos últimos três anos do recorte temporal da pesquisa, houve um crescimento linear e uma clara regularidade na disponibilização de aplicativos cívicos em comparação aos anos anteriores. Também foi interessante perceber que nenhum dos aplicativos cívicos identificados foi disponibilizado para o uso do cidadão no ano de 2014, talvez a eleição presidencial tenha contribuído como fator para a ausência de aplicativos disponibilizados nesse ano.

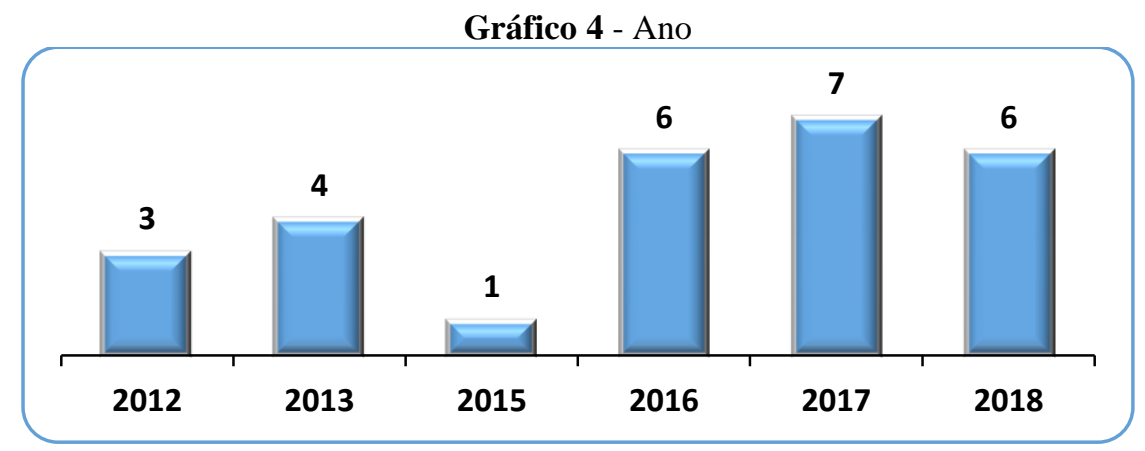

Fonte: Elaborado pelos autores. 


\subsection{Tipo de Licença}

Para o recorte metodológico dessa pesquisa, a licença do aplicativo poderia ser categorizada como paga ou gratuita, e todos os 27 aplicativos têm ou tinham a licença de uso $100 \%$ gratuita. Essa disponibilização de acesso sem ônus se configura numa característica importante para o exercício da cidadania digital, pois colabora na garantia do exercício gratuito dos direitos políticos, sociais e/ou civis por meio da tecnologia.

Gráfico 5 - Licença

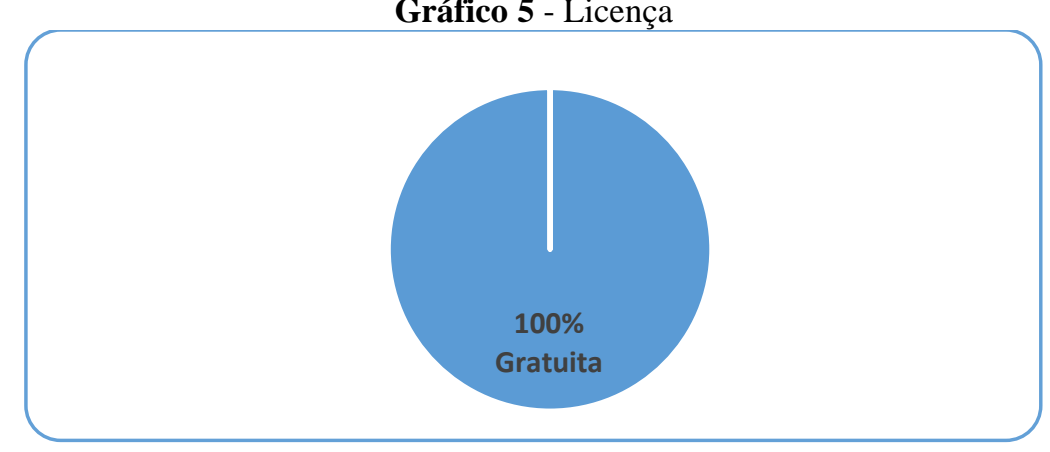

Fonte: Elaborado pelos autores.

\subsection{Sistema Operacional}

Dado que o sistema operacional iOS é utilizado apenas em smartphones da empresa Apple, aparelhos esses de alto custo financeiro para a maioria dos brasileiros, compreende-se a relevância no fato de $100 \%$ dos aplicativos cívicos identificados serem compatíveis com o sistema Android. É perceptível a maneira como esse dado contribui significativamente para o exercício da cidadania digital, especialmente quanto à inclusão digital. Por outro lado, e também relevante, a compatibilidade com o sistema iOS é alto, 96\%, apenas um aplicativo não era compatível. 


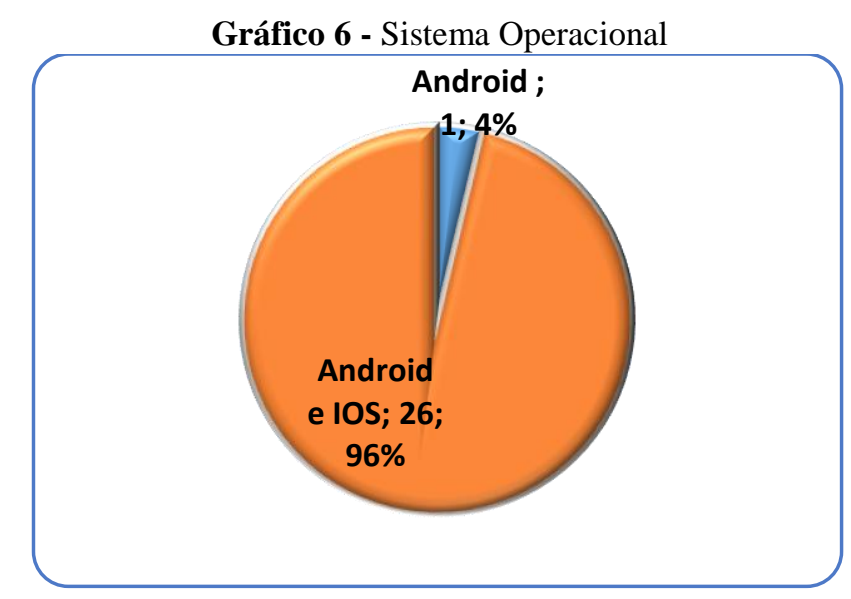

Fonte: Elaborado pelos autores.

\subsection{Ferramentas Cívicas}

$\mathrm{Na}$ análise de conteúdo foram identificadas 7 (sete) ferramentas cívicas cujas funcionalidades e recursos configuram a participação social voltada para o exercício da cidadania digital via aplicativos cívicos. Nesse sentido, se identificou e registrou, para cada aplicativo, quais as ferramentas cívicas disponibilizadas.

Em grande parte dos aplicativos foi possível observar mais de uma ferramenta cívica disponível para o cidadão, razão pela qual o percentual de distribuição se apresenta tão equilibrado. O acompanhamento foi a ferramenta com maior quantitativo de disponibilização para uso, seguido da fiscalização. A denúncia e cobrança foram as ferramentas cívica com menores índices de disponibilização.

Gráfico 7 - Ferramentas cívicas

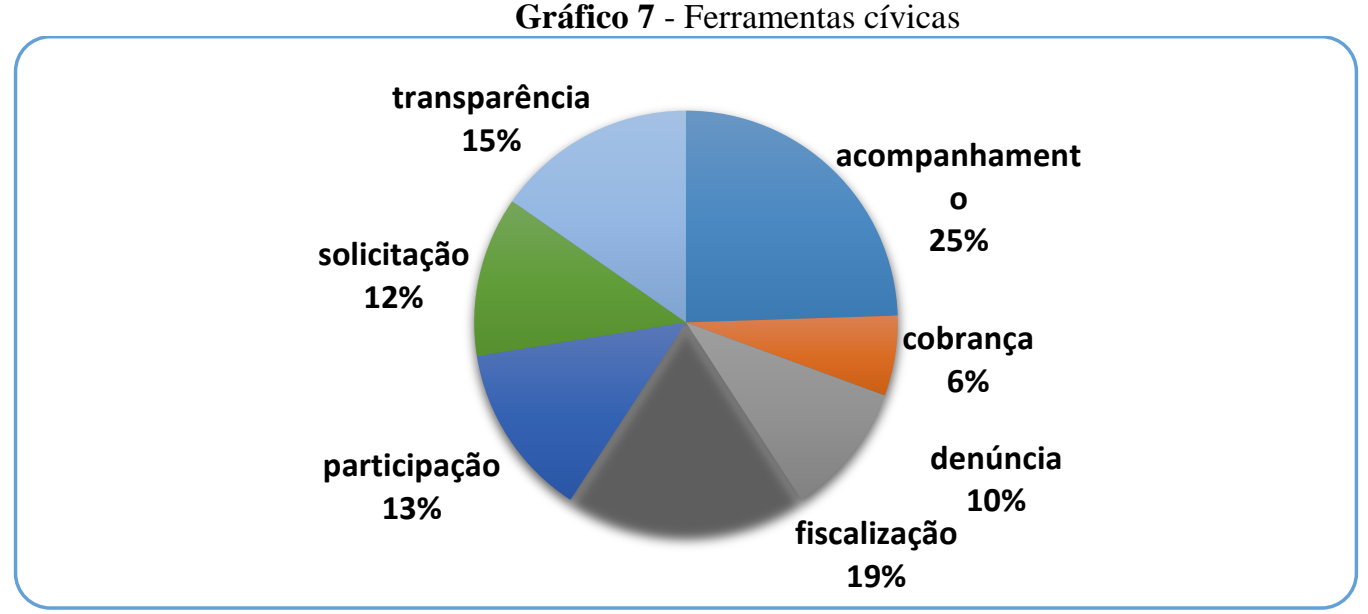

Fonte: Elaborado pelos autores. 


\subsection{Fontes de dados}

Dentre as fontes de dados que alimentam os aplicativos cívicos identificados, os Dados Governamentais Abertos são a fonte mais utilizada no desenvolvimento dos aplicativos, corresponde a quase 65\%, seguido pelos dados da interação entre o cidadão e as prefeituras. Cerca de $3 \%$ das fontes de dados vêm de outras fontes, tais como processos judiciais oriundos do Supremo Tribunal Federal e do Superior Tribunal de Justiça, que não se configuram como dados governamentais abertos devido às particularidades legais das ações judiciais.

\section{Gráfico 8 - Fonte de Dados}

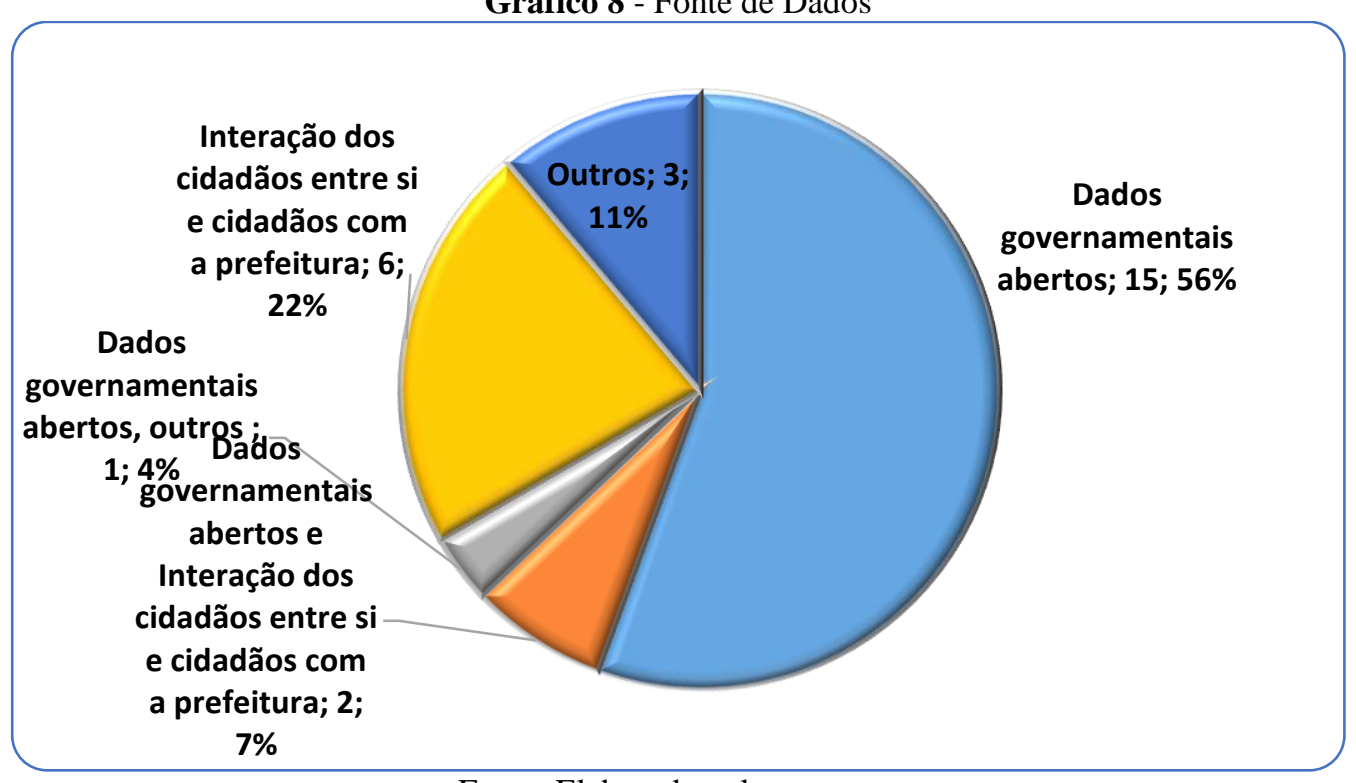

Fonte: Elaborado pelos autores.

\subsection{Status do aplicativo}

A maioria dos aplicativos está ativa e disponível para download no Google Play Store e na Apple Store, porém é preocupante o alto índice de aplicativos cívicos inativos, quase $30 \%$. A partir da análise dessa inatividade, podem-se levantar possíveis causas dos aplicativos inativos e consequente interferência no exercício da cidadania digital. Dos 8 aplicativos inativos, 3 são do tema política partidária e 2 são do tema interação urbana, justamente dois dos três temas mais recorrentes. Isso pode corroborar com a inferência apresentada no Gráfico 1 da alta concentração temática, o que gera a duplicidade de esforços e 
concorrência por fomento, as quais pouco contribuem com o desenvolvimento da cidadania digital no país.

\section{Gráfico 9 - Status}

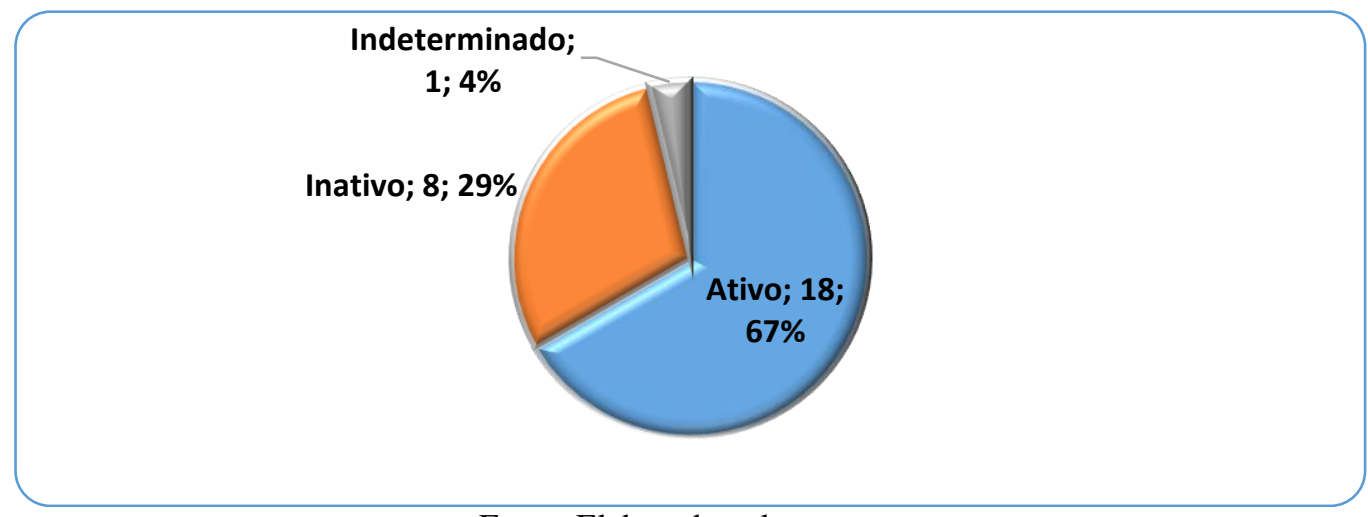

Fonte: Elaborado pelos autores.

\section{Conclusão}

Nessa pesquisa, a cidadania digital foi vislumbrada como direito e a vontade do cidadão em atuar como protagonista, em participar ativamente em ações públicas que interferem na sua vida. Para tanto, os aplicativos cívicos em celulares smartphones foram tidos como ferramentas importantes para a construção de uma cidadania mais ampla e democrática.

O panorama delineado nesta pesquisa permite responder à questão norteadora: como a cidadania digital tem sido exercida no Brasil por meio dos aplicativos cívicos desenvolvidos? Respondendo a esta questão, observa-se um cenário por vezes bastante concentrado, como nos autores e nos temas dos aplicativos cívicos, mas também disperso, como nas ferramentas cívicas disponibilizadas. Ela está concentrada em algumas categorias, especialmente quanto aos tipos de autores dos aplicativos e quanto aos temas. Porém, também foi identificado um cenário de dispersão, pois há uma variedade importante nas ferramentas cívicas disponibilizadas pelos aplicativos para exercício da cidadania digital.

Um aspecto importante da análise consistiu do tipo de autoria dos aplicativos cívicos. Observou-se que o Governo Federal e Estadual, bem como as prefeituras, são as entidades que atualmente ditam o caminho da cidadania 
digital no país, pois são os principais desenvolvedores dos aplicativos. Esse cenário parece ser um reflexo da cidadania exercida de uma maneira geral no Brasil: "de cima para baixo". Essa percepção só reforça a necessidade de a sociedade civil estar mais presente e ativa nessa realidade digital, em busca de seus interesses.

Já numa perspectiva mais democrática, nota-se que o sistema operacional Android é plataforma de grande parte dos aplicativos cívicos, sendo esse um fator que colabora com o exercício da cidadania digital ao incluir grupos mais diversos e de diferentes classes sociais. Daí a relevância em se pesquisar aplicativos móveis, considerando que eles são ferramentas importantes para dinamizar tais acessos de maneira democrática, já que os aparelhos celulares que utilizam esse sistema são os mais variados em opções para aquisição, numa relação de custo benefício. Ainda que a inclusão digital não tenha feito parte da análise desse estudo, tal dado está diretamente relacionado à questão, razão pela qual é importante pontuar.

Além disso, é importante salientar que as ferramentas cívicas identificadas nos aplicativos cívicos apresentaram um panorama da cidadania digital que parece ter muita relação com o interesse de quem os desenvolve, o que não necessariamente corrobora com o interesse de quem os utiliza, o cidadão. O acompanhamento e a fiscalização foram as ferramentas mais disponibilizadas, mas não é possível saber se são as ferramentas que atendem mais aos anseios da sociedade, bem como se são as ferramentas que estão mais alinhadas ao conceito de cidadania digital quanto aos direitos e deveres cívicos proporcionados.

Já os Dados Governamentais Abertos (DGA) se apresentaram como uma fonte de dados bastante utilizada por diversos autores e em temáticas distintas. Foi interessante observar a importância que o uso dos DGA tem para o desenvolvimento da cidadania digital no Brasil, pois ficou claro que sem eles, a quantidade de aplicativos cívicos disponíveis no país seria muito menor. Esse é um aspecto que precisa ser incentivado à continuidade, pois depende de políticas públicas que garantam a transparência e a disponibilização aberta dos dados públicos para o uso. 
Por isso, dentre as principais contribuições desse trabalho, acredita-se estar o panorama do cenário da cidadania digital por meio dos aplicativos cívicos desenvolvidos, quais as temáticas mais abordadas nessas plataformas, assim como as funções e ferramentas disponíveis para o cidadão. Este trabalho contribui não apenas para a percepção do percurso da cidadania digital no Brasil, sob o olhar da Ciência da Informação, mas também no início da busca pelo entendimento de como está sendo construída uma memória coletiva social sobre a realidade de um bairro, de uma cidade, de um estado e/ou de um país, numa perspectiva que envolve cidadania e democracia na web.

Os aplicativos cívicos refletem uma memória coletiva de temática específica, porém formada por múltiplas realidades e voltada para o mesmo fim: o exercício da cidadania digital. Assim, o panorama apresentado nessa pesquisa relaciona em sua essência a informação pública, a memória e a tecnologia, pois compreende a comunicação e a visualização dessa memória coletiva como fenômeno da socialização do conhecimento dos cidadãos e das administrações públicas por intermédio das tecnologias de informação e comunicação.

Também a partir do panorama apresentado é possível pensar em novas linhas de pesquisa, como por exemplo, na organização dessa memória coletiva social ou conhecimento registrado, em como gerenciar essas informações ricas em conteúdo e produzidas por demandas, desejos, interação e percepção social. Tais informações podem também ser analisadas visando obter tendências e caminhos para a continuidade da cidadania digital no país. Já que essas informações são produzidas de forma espontânea, por cidadãos engajados, elas são resultado de um pensamento coletivo crítico e seria um desperdício imensurável não (re)utilizá-las em ações concretas de políticas públicas.

Para trabalhos futuros, aponta-se como importante o estudo de formas de reutilizar os dados e informações produzidas nos aplicativos cívicos utilizando tecnologias dos dados abertos vinculados, do inglês Linked Open Data (LOD), por permitir publicar e conectar dados de forma estruturada na web, podendo assim colaborar no desenvolvimento e fortalecimento da cidadania digital no Brasil. Outro trabalho futuro importante seria levantar o perfil dos cidadãos que utilizam esse tipo de aplicativo, via análise do perfil e conteúdo das informações 
produzidas por eles na interação com outros cidadãos ou com órgãos da administração pública, isto pode contribuir com novas estratégias para o desenvolvimento da cidadania digital no Brasil.

Por fim, acredita-se verdadeiramente que a cidadania digital é um caminho sem volta na relação entre sociedade e Estado. É notório que as pessoas querem participar, que elas desejam falar e ser ouvidas e que a Internet tem um papel fundamental nessa relação. O Estado precisa acolher essas demandas com novos modelos de governança digital e apresentar perspectivas reais de atendê-las, pois isso não é um favor ao cidadão, é um direito. Foi possível perceber que a Ciência da Informação pode colaborar de forma mais efetiva com o desenvolvimento da cidadania digital no Brasil por meio da organização, recuperação e disseminação da informação pública, bem como com a visualização da memória coletiva construída por cidadãos interessados e engajados com o país, através dos aplicativos cívicos em celulares smartphones.

\section{Referências}

AZEVEDO, M. M. V. de. Algumas considerações acerca de uma democracia direta eletrônica. DataGramaZero, Rio de Janeiro, v. 13, n. 4, 2012.

BARROS, S. Os desafios das consultas públicas online: lições do marco civil da Internet. Liinc em revista, Rio de Janeiro, v. 12, n. 1, 2016.

BORGES, J.; SILVA, H. P. Democracia eletrônica e competência informacional. Informação \& Sociedade: Estudos, João Pessoa, v. 16, n. 1, p. 129-137, 2006.

BRISOLA, A. C. A.S. A ágora digital, a competência crítica em informação e a cidadania ampliada: uma construção possível. 2016. (Dissertação de mestrado). Universidade Federal do Rio de Janeiro. Rio de Janeiro. 2016.

CARVAlHO, A. M. G. de; AMÉRICO, M. Inclusão e Cidadania Digital no Brasil: a (des) articulação das políticas públicas. Redes.com (Sevilla), v. 1, p. 69-84, 2014.

CARVAlHO, A. M. G. de; SANTOS, P. L. V. A. C. Cidadania digital e a distribuição da informação nos projetos governamentais. In: ENCONTRO NACIONAL DE PESQUISA EM CIÊNCIA DA INFORMAÇÃO, 10, 2009, João Pessoa. Anais [...]. João Pessoa: ANCIB, 2009. p. 1-20. 
CASTELLS, M. The Internet galaxy, reflections on the Internet, business and society. Oxford: Oxford University Press, 2001.

CERQUINHO, K. G.; TAVARES, W.; DE PAULA, A. P. P. Movimento minas: a participação cidadã via Internet no estado de minas gerais. Perspectivas em Gestão \& Conhecimento, João Pessoa, v. 4, n. 1, p. 218-236, 2014.

GOMES, J. C.; SCHNEIDER, M. A. F.; BEZERRA, A. C. Aplicativos Cívicos: apropriação de dados abertos governamentais pela sociedade. In: ENCONTRO NACIONAL DE PESQUISA EM CIÊNCIA DA INFORMAÇÃO, 19, 2018. Londrina. Anais [...]. Londrina: ANCIB, 2018. p. 3153-3167.

JAMBEIRO, O., SOBREIRA, R., MACAMBIRA, L. Informação, participação cívica e controle da gestão pública: análise dos websites das capitais brasileiras. In: ENCONTRO NACIONAL DE PESQUISA EM CIÊNCIA DA INFORMAÇÃO, 12., 2011, Brasília. Anais [...]. Brasília: ANCIB, 2011. p. 1461-1482.

JANUÁRIO, Sandryne Bernardino Barreto; CORREA, Renato Fernandes. Contribuições da Ciência da Informação para a cidadania digital no Brasil: a participação social em questão. Em Questão, Porto Alegre, v. 26, n. 2, p. 306329. 2020.

MOREIRA, D. L. J. Panorama sobre a utilização de dados governamentais abertos no Brasil: um estudo a partir dos aplicativos desenvolvidos. 2015 Dissertação (Mestrado em Ciência da Informação) - Universidade Federal do Rio de Janeiro, Rio de Janeiro, 2015.

PARRA FILHO, H. C. P.; MARTINS, R. A. P. Governança digital como vetor para uma nova geração de tecnologias de participação social no brasil. Liinc em revista, Rio de Janeiro, v. 13, n. 1, 2017.

RIBEIRO, H. C. L. Participação política a partir de iniciativas online: possibilidades, limites e desafios para a democracia. 2017. Dissertação (Mestrado em Ciência da Informação) - Universidade Federal do Rio de Janeiro, Rio de Janeiro, 2017.

ROCHA, M. P. C.. A questão cidadania na sociedade da informação. Ciência da Informação, Brasília, v. 29, n. 1, jan./abr. 2000.

SANTOS, J. C. Informação pública e participação política em rede: uma análise da governança eletrônica nos websites dos deputados do Estado da Bahia. Dissertação (Mestrado em Ciência da Informação) - Programa de PósGraduação em Ciência da Informação, Universidade Federal da Bahia, 2011.

TESTA, A. N. F. V. Cidadania digital e competitividade. Inclusão Social, v. 2, n. 1, p. 67-72, 2007. 


\title{
Citizenship at your fingertips: a panorama through civic app in Brazil
}

\begin{abstract}
This works aim to analyze the exercise of digital citizenship in Brazil through the civic applications made available between 2012 and 2018. The methodology is exploratory and descriptive research, based on documentary research and content analysis. The data acquisition took place between June 2017 and December 2018 and used four main sources of information. Twentyseven civic applications were identified and by consulting digital documents (on websites, blogs, news and social networks), nine categories or units of analysis were raised. The applications were categorized and a data analysis was performed using graphics to understand the exercise of digital citizenship in the country through the available applications. It concludes that the exercise of digital citizenship in Brazil presents a scenario on the one hand condensed in some values of categories, such as the authors and themes of civic applications, on the other hand dispersed as in the civic tools that enable digital citizenship in the country.
\end{abstract}

Keywords: Digital citizenship. Civic apps. Civic technology. Digital democracy. Social participation.

Recebido: $12 / 02 / 2020$

Aceito: 30/04/2020

\section{Como citar:}

JANUÁRIO, Sandryne Bernardino Barreto; CORREA, Renato Fernandes. A cidadania nas pontas dos dedos: um panorama por meio dos aplicativos cívicos no Brasil. Em Questão, Porto Alegre, v.27, n. 1, p. 160-184, 2021. Doi:

http://dx.doi.org/10.19132/1808-5245271.160-184 